\title{
ANÁLISE DO CURSO DE ENGENHARIA DE BIOPROCESSOS DA UNIVERSIDADE FEDERAL DE SÃO JOÃO DEL-REI A PARTIR DA PESQUISA DE EGRESSOS
}

Anderson Ravikdos Santos - anderson.ravik@gmail.com

Camila de Sousa Ferreira - camiladesousam@gmail.com

PaolaLima Oliveira-paolaloliveira94@yahoo.com.br

Laura Carpinetti Galdino - lauracarpinetti@outlook.com

Daniela Leite Fabrino - danifabrino@ufsj.edu.br

Universidade Federal de São João del-Rei - Campus Alto Paraopeba, Departamento de Química, Biotecnologia e Engenharia de Bioprocessos

Rodovia MG-443, km 7 - Fazenda do Cadete

36420-000 - Ouro Branco - Minas Gerais

Resumo: Com o intuito não só de atender às demandas de trabalho da região do Alto Paraopeba mas também de diversificá-las, a Universidade Federal de São João del-Rei oferta o curso de Engenharia de Bioprocessos no campus Alto Paraopeba. O presente trabalho objetivou realizar uma diagnose deste curso a partir de uma pesquisa de egressos robusta e se justifica pela ausência de uma gestão estratégica do portal de egressos da universidade e o desafio de manter uma ferramenta mais efetiva de comunicação entre os ex-alunos e a instituição. Também, pela ausência de um perfil fiel aos egressos que balize o Colegiado e o Núcleo Docente Estruturante nas ações de melhorias e divulgação do curso à sociedade e ao corpo discente com a visão do mercado de trabalho desses profissionais. Por meio de um questionário, dividido em três seções, foram quantificados e qualificados parâmetros relacionados aos aspectos gerais do egresso, aos aspectos gerais do curso e do campus e ao mercado de trabalho. Os resultados obtidos apontam que, de uma forma geral, o maior problema enfrentado pelos egressos é um mercado de trabalho que ainda não conhece o Engenheiro de Bioprocessos, visto que embora a maioria dos egressos se encontre satisfeita com o curso e com sua situação profissional, sua remuneração ainda está abaixo do esperado para suas colocações. Mais que uma pesquisa pontual, pretendeu-se com este trabalho inspirar uma forma institucional de acompanhar os egressos em um período continuado para verificar como se desenvolvem no mercado de trabalho e com isso, avaliar a qualidade do ensino oferecido.

Palavras-chave: Pesquisa de Egressos. Engenharia de Bioprocessos. Ensino Superior.

\section{INTRODUÇÃO}

O Campus Alto Paraopeba da Universidade Federal de São João del-Rei (UFSJ CAP) surgiu em 2007 tendo como justificativa o fato da região abrigar um dos mais importantes complexos de mineração e metalurgia de ferro do planeta, abrangendo aproximadamente 20 cidades, entre elas Ouro Branco-MG. Além disso, o Alto Paraopeba está próximo à região metropolitana de Belo Horizonte, onde já se consolidou e está em franca expansão uma bem- 
sucedida rede de inovação tecnológica e de empresas na área de biotecnologia (NUCCI et. al, 2017).

Com o intuito de atender as demandas regionais de trabalho e diversificar a economia local, a UFSJ CAP oferta cinco cursos de engenharia, dentre eles a Engenharia de Bioprocessos. O Engenheiro de Bioprocessos utiliza sistemas biológicos, organismos vivos ou derivados destes nas áreas da saúde, agricultura, alimentos e bebidas, energia, meio ambiente, indústria bioquímica, melhoramento genético, tratamento e aproveitamento de resíduos (KRÜGER, J. 2018). Além disso, na área da saúde, também atua no desenvolvimento de vacinas e novos testes diagnósticos. Com os avanços da biotecnologia e a necessidade de produtos farmacêuticos e de fontes sustentáveis de combustíveis, a formação de engenheiros nesta área é de suma importância para atender às novas demandas da sociedade (UTFPR, 2018).

O Engenheiro de Bioprocessos da UFSJ tem formação nas áreas básicas de química, física, matemática, computação e biologia, estando apto a desenvolver e aperfeiçoar produtos e processos baseados no emprego, em escala industrial, de enzimas, microrganismos e células vivas. Dessa forma, espera-se que o aluno egresso consiga desenvolver e utilizar novas tecnologias; gerenciar, operar e manter sistemas e processos; avaliar criticamente ordens de grandeza e significância de resultados; comunicar-se eficientemente nas formas escrita, oral e gráfica; atuar em equipes multidisciplinares e conhecer métodos e técnicas de investigação e elaboração de trabalhos técnicos e científicos. (CBIOP, 2020).

O presente trabalho visou realizar uma diagnose do curso de Engenharia de Bioprocessos da UFSJ CAP e ser uma ferramenta para a autoavaliação e aperfeiçoamento do curso. Sua importância se faz pela ausência de uma gestão estratégica de melhoria institucional na coleta dos dados do portal de egressos da UFSJ, pelos desafios de manter uma ferramenta efetiva de comunicação entre os egressos e a instituição e pela ausência de um perfil mais fidedigno aos egressos que balize o Colegiado e o Núcleo Docente Estruturante nas ações de melhorias e divulgação do curso à sociedade e ao corpo discente com a visão do mercado de trabalho desses profissionais.

De acordo com Lousada e Martins (2003) egresso é aquele que efetivamente concluiu os estudos, recebeu o diploma e está apto a ingressar no mercado de trabalho, como fator de destaque e fonte de informação à instituição de ensino superior que o formou, não considerando, portanto, os alunos transferidos, evadidos e jubilados. Esta foi a definição utilizada para definir o público abordado neste trabalho.

Mais que uma pesquisa pontual, pretende-se com este trabalho inspirar uma forma institucional de acompanhar os egressos em um período continuado para verificar como se desenvolvem no mercado de trabalho e com isso, avaliar a qualidade do ensino oferecido.

\section{METODOLOGIA}

Para a realização da pesquisa construiu-se, com o auxílio da Secretaria Integrada de Coordenações de Curso do CAP, um banco de dados contendo as informações de contato dos alunos egressos do curso de Engenharia de Bioprocessos. Segundo os dados do Sistema de Controle Acadêmico (CONTAC) da UFSJ, a Engenharia de Bioprocessos contava, em março de 2020, com 195 alunos formados.

Elaborou-se um instrumento de pesquisa utilizando a ferramenta Formulários, da plataforma eletrônica Google Docs e a fim de garantir a privacidade dos participantes, a coleta de dados ocorreu de forma anônima. O acesso ao formulário se deu por meio de links enviados aos egressos que aceitaram participar da pesquisa. 
Para melhor organização e entendimento, o formulário foi dividido em 3 seções de perguntas: a primeira consistia no levantamento de informações preliminares a respeito dos egressos e algumas percepções pessoais; a segunda abordava aspectos gerais do curso e do campus; a terceira e última consistia em levantar dados sobre a inserção e desenvolvimento dos egressos no mercado de trabalho e seu interesse em uma pós-graduação.

Realizaram-se ligações telefônicas individuais aos egressos a fim de explicar-lhes o intuito da pesquisa e convidá-los a participar. Os egressos que não atenderam as ligações foram contatados por outros meios como e-mail, Whatsapp, Facebook e Instagram, de modo a oportunizar que o maior número possível de pessoas participasse da pesquisa. Todos os resultados gerados pelo formulário foram transferidos para o Excel para a elaboração de gráficos a partir dos quais foram feitas as análises dos resultados.

Nesta pesquisa, todos os alunos egressos do curso de Engenharia de Bioprocessos representaram a população, ou seja, conjunto total de elementos estudados (PATINO; FERREIRA, 2015). Os egressos que aceitaram participar e preencheram o formulário representaram a amostragem, que, segundo Cunha e Beuren (2006), viabiliza a coleta dos dados requeridos em um estudo sem a necessidade de estudar toda a população.

Foi estabelecido um nível de confiança, que indica qual a confiabilidade dos resultados estimados na população de estudo (PATINO; FERREIRA, 2015) e uma margem de erro, que representa a diferença entre os resultados obtidos na amostra em relação ao valor real da população (KIEHL, 1970).

\section{RESULTADOS E DISCUSSÃO}

Da população total de 195 egressos, obteve-se 144 participações. Inserindo o valor desta amostragem e população na calculadora virtual de margem de erro oferecida pela plataforma Solvis, obteve-se (para um nível de confiança de 95\%) uma margem de erro amostral igual a $4,19 \%$. Ou seja, as respostas da população podem variar 4,19\% em relação às respostas obtidas com a amostra, porém há $95 \%$ de chance dos resultados obtidos representarem toda a população (SOLVIS, 2020).

Na primeira seção, que trata sobre os aspectos gerais do egresso, obteve-se a informação de que a maioria dos profissionais formados no curso de Engenharia de Bioprocessos são mulheres: 79,9\% dos egressos; um fato que contribui para mostrar como as mulheres vêm rompendo o paradigma de que a Engenharia seja um campo estritamente masculino. Quando se compara a idade dos egressos, percebe-se que a faixa etária predominante está entre 26 e 30 $\operatorname{anos}(71,5 \%)$.

A maioria dos participantes da pesquisa $(46,5 \%)$ cursou o Ensino Médio totalmente em escola pública enquanto $40,3 \%$ cursaram totalmente em escola particular e a pequena parcela restante cursou em ambas as modalidades. Este resultado corrobora com a reserva de metade das vagas do curso para alunos oriundos da rede pública de ensino, que ocorre desde quando o ingresso na universidade se dava por meio do vestibular. $\mathrm{O}$ vestibular inclusive foi outro ponto de destaque nos resultados, sendo a forma mais recorrente de ingresso no curso: 81,9\%, como mostra a Figura 1. Este resultado é reforçado pelo fato de que só a partir do segundo semestre de 2013 a UFSJ passou a adotar o Sistema de Seleção Unificada (Sisu) como forma principal de ingresso em seus cursos de graduação. 
Figura 1 - Modalidade de ingresso no curso.

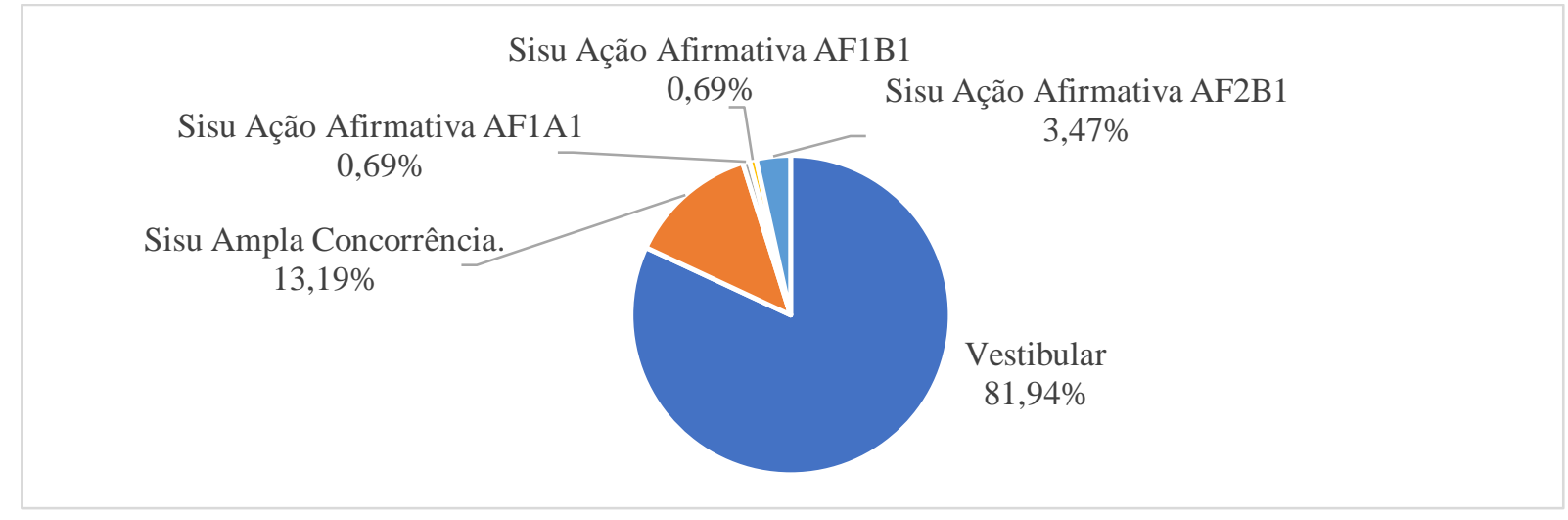

Fonte: Autoria própria

Se tratando do tempo que os egressos levaram para se formar (Figura 2), 29,2\% concluíram a graduação no tempo previsto de 5 anos ou menos, 39,6\% levaram até um ano a mais para se formar e o restante mais de 1 ano além do previsto.

Figura 2 - Tempo que os egressos levaram para concluir a graduação.

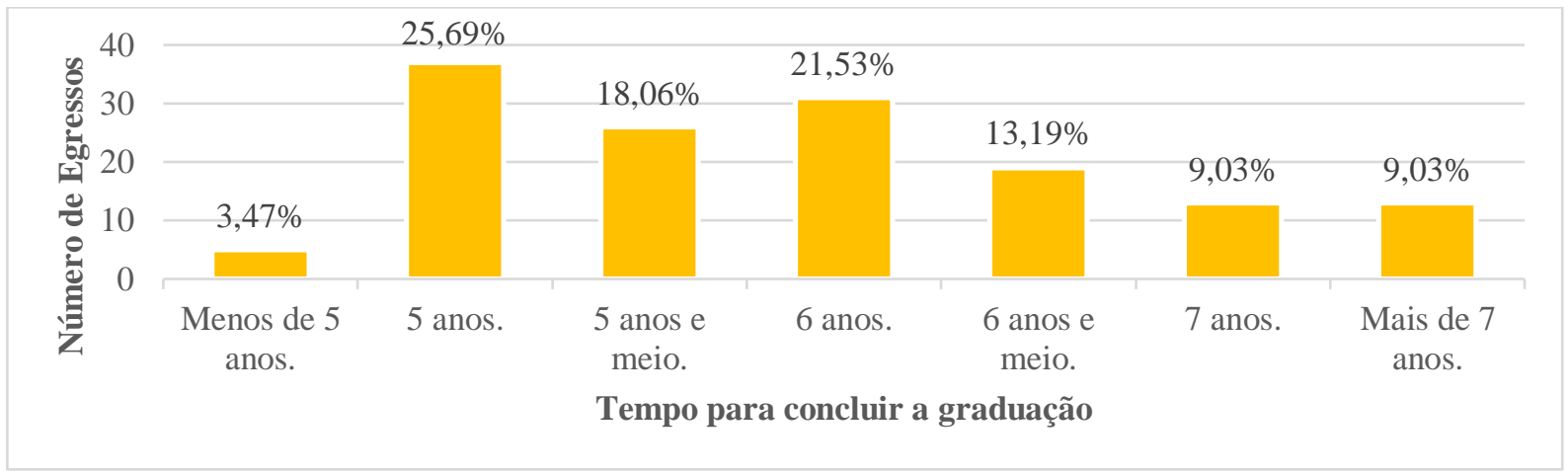

Fonte: Autoria própria

O principal motivo que levou os egressos a escolherem a Engenharia de Bioprocessos foi a afinidade com a área $(82,6 \%)$ como aponta a Figura 3, seguida da ampla possibilidade de atuação (33,3\%). Este último dado quando comparado aos resultados da terceira seção, que apresenta a variedade de áreas em que os profissionais atuam, mostra que a formação interdisciplinar deste engenheiro cumpre sua função e as expectativas dos estudantes que buscam se capacitar para uma ampla possibilidade de atuação. A escolha pelo Campus Alto Paraopeba ter-se dado principalmente pela sua localização $(66,7 \%)$ mostra a assertividade da decisão de instalar do Campus nesta região, que carecia de uma Instituição Federal de Ensino Superior nas décadas passadas. Inclusive, a grande maioria dos egressos já morava em Minas Gerais antes de ingressar na universidade $(93,8 \%)$. 
Figura 3 - Motivação para escolha do curso de Engenharia de Bioprocessos.

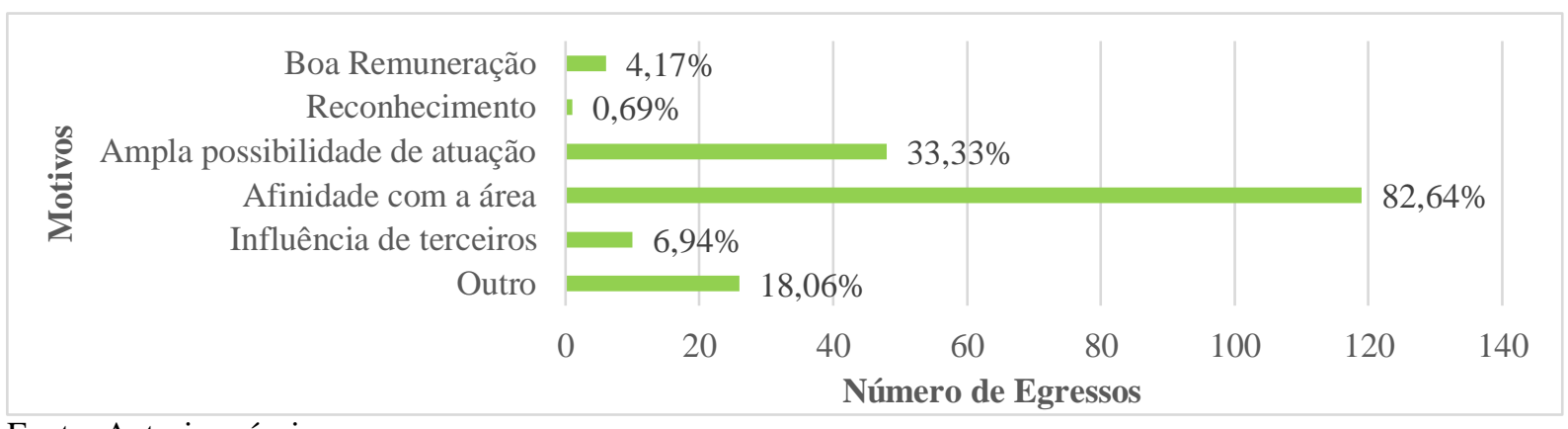

Fonte: Autoria própria

No que se refere aos principais tipos de bolsa recebidos durante a graduação pelos egressos, destacaram-se monitoria e iniciação científica com 32,64\% dos egressos tendo recebido cada uma delas. Apenas 35,4\% não receberam nenhum tipo de bolsa.

Dos participantes da pesquisa, $40 \%$ exerceram alguma atividade remunerada durante o curso (Figura 4). Esse dado comparado à Figura 1 mostra que a reserva de vagas, não só para alunos oriundos do ensino público mas também para os alunos de baixa renda, é realmente importante, pois grande parte dos egressos precisou dividir seu tempo entre formação acadêmica e manutenção monetária própria para conseguir concluir seu curso. Mostra ainda a importância do curso noturno oferecido pela instituição e acima de tudo a importância da existência do ensino público de formação superior, que muitas vezes é questionado pela sociedade.

Figura 4 - Egressos que exerceram atividade remunerada durante a graduação.

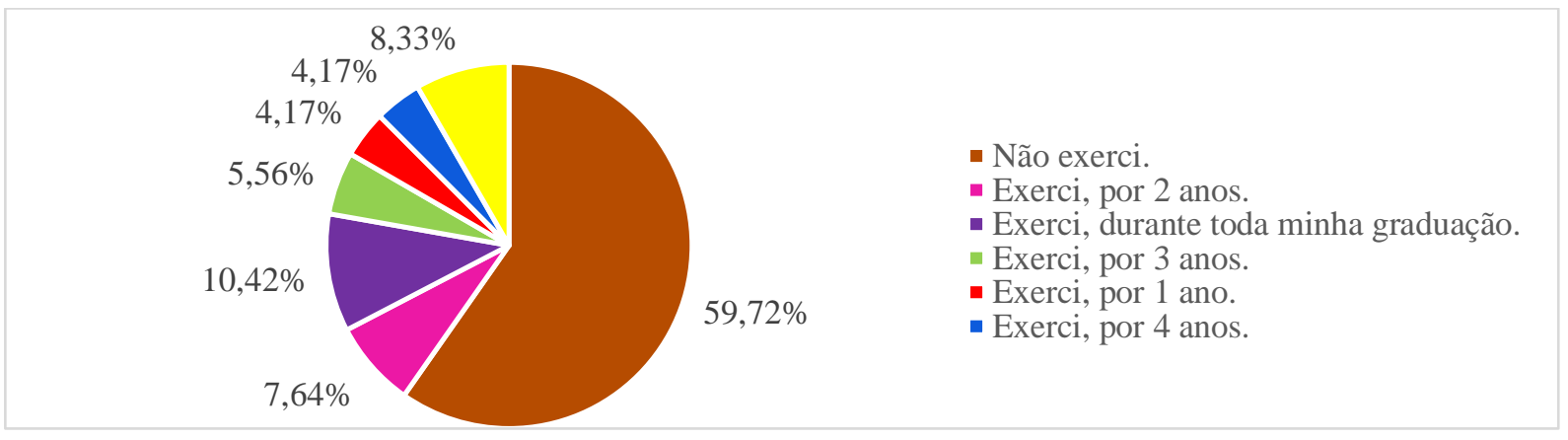

Fonte: Autoria própria

A segunda seção da pesquisa abordou aspectos gerais do curso e do campus dentro da escala Likert (de péssimo a excelente). Os resultados obtidos estão dispostos na Figura 5. 
Figura 5 - Avaliação dos aspectos gerais do curso de Engenharia de Bioprocessos e do Campus Alto Paraopeba da UFSJ pelos egressos.

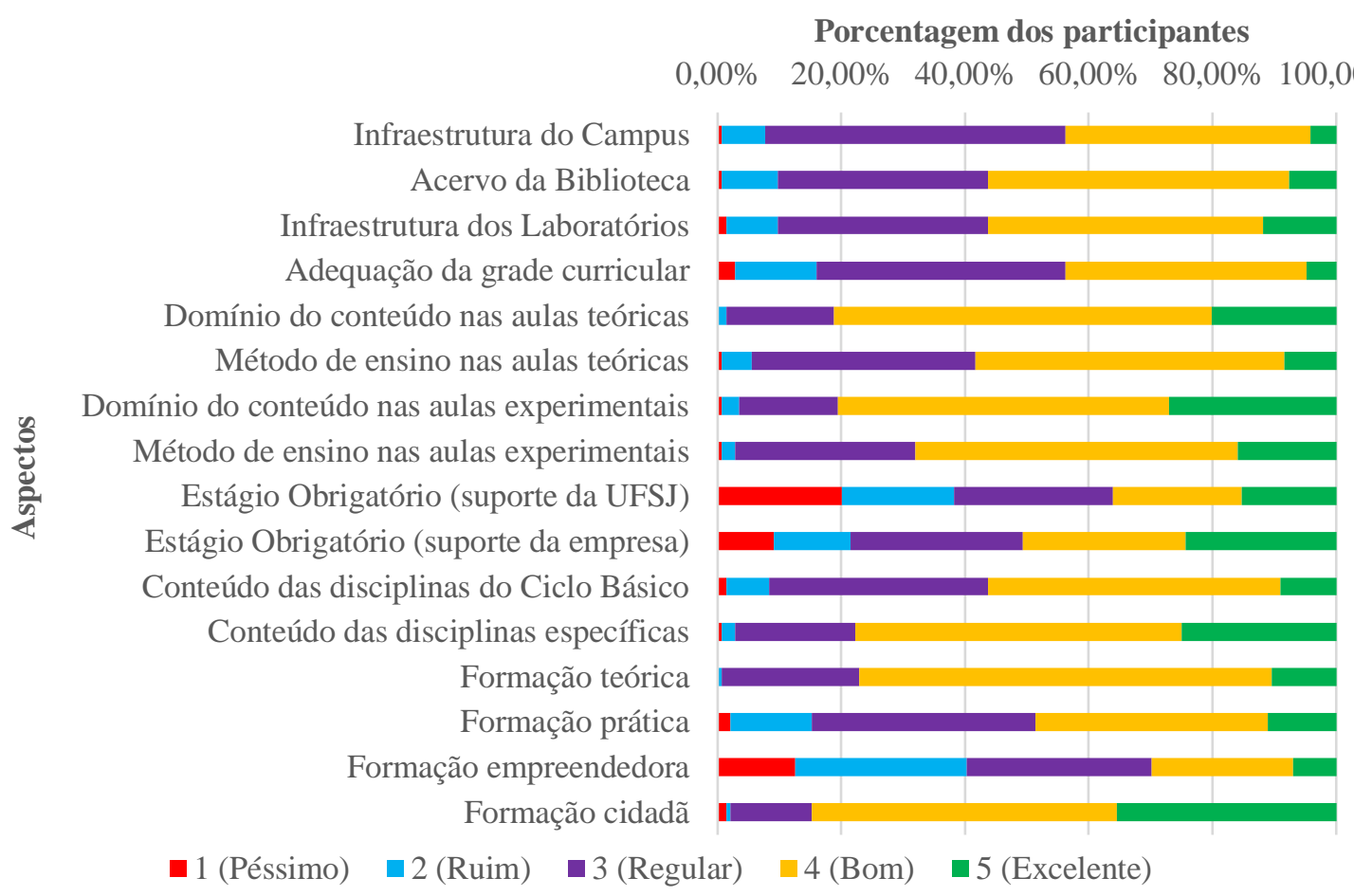

Fonte: Autoria própria

Observa-se a partir dos resultados um equilíbrio nas avaliações quanto à infraestrutura do campus: $45,8 \%$ a consideraram regular e $43,8 \%$ boa. Também em relação ao acervo da biblioteca a maioria dos participantes o classificou como bom $(48,6 \%)$ ou regular $(34 \%)$, o que indica neste sentido um bom suporte para os estudos dos alunos e, com isso, maior segurança em sua formação. Em relação à infraestrutura dos laboratórios, a opção boa se destaca entre as demais respostas com 44,4\%.

Em relação à adequação da grade curricular com a realidade do mercado de trabalho, as principais respostas se dividiram entre boa $(38,9 \%)$ e regular $(40,3 \%)$. No que tange os docentes do curso, os resultados indicam uma satisfação dos egressos em relação ao domínio dos conteúdos lecionados e o método de ensino utilizados tanto em aulas teóricas quanto práticas: todos estes aspectos foram avaliados como bons por pelos menos metade dos egressos, chegando a mais de $60 \%$ quando se trata do domínio do conteúdo das aulas teóricas por parte dos docentes.

A respeito do estágio obrigatório, no que se refere ao suporte da universidade e da empresa, as avaliações mostram a necessidade de melhorias no programa por parte da universidade, pois $25,7 \%$ o classificaram como regular, $20,8 \%$ como bom e $20,1 \%$ como péssimo enquanto no que se refere ao suporte da empresa empregadora, a maioria dos resultados se enquadram entre $27,8 \%$ para regular, $26,4 \%$ para bom e $24,3 \%$ para excelente. Infere-se com isso que os egressos receberam durante o estágio suporte mais efetivo da empresa que da universidade.

Tanto os conteúdos das disciplinas do ciclo básico quanto das disciplinas específicas e profissionalizantes foram avaliados majoritariamente como bons: $47,2 \%$ e $52,8 \%$ respectivamente. Das respostas obtidas em relação ao tipo de formação, $66,7 \%$ consideram sua 
formação teórica boa, enquanto a formação prática teve uma divisão entre $36,1 \%$ que a consideram regular e $37,5 \%$ boa.

Em relação à sua formação empreendedora, 29,9\% dos participantes a consideram regular e se tratando da formação cidadã $49,3 \%$ a avaliam como boa. Sabe-se que as disciplinas de formação geral que o curso possui e tratam de empreendedorismo não são suficientes para abranger todo o conhecimento necessário para o engenheiro administrar um negócio, o que pode justificar a avaliação insatisfatória que esse tipo de formação recebeu.

Outro ponto de destaque nos resultados obtidos diz respeito ao nível de satisfação com o curso de Engenharia de Bioprocessos: $65,7 \%$ dos participantes se disseram muito satisfeitos, como mostra a Figura 6, e 85,4\% dos participantes indicariam o curso para outras pessoas.

Figura 6 - Nível de satisfação dos egressos com o curso de Engenharia de Bioprocessos.

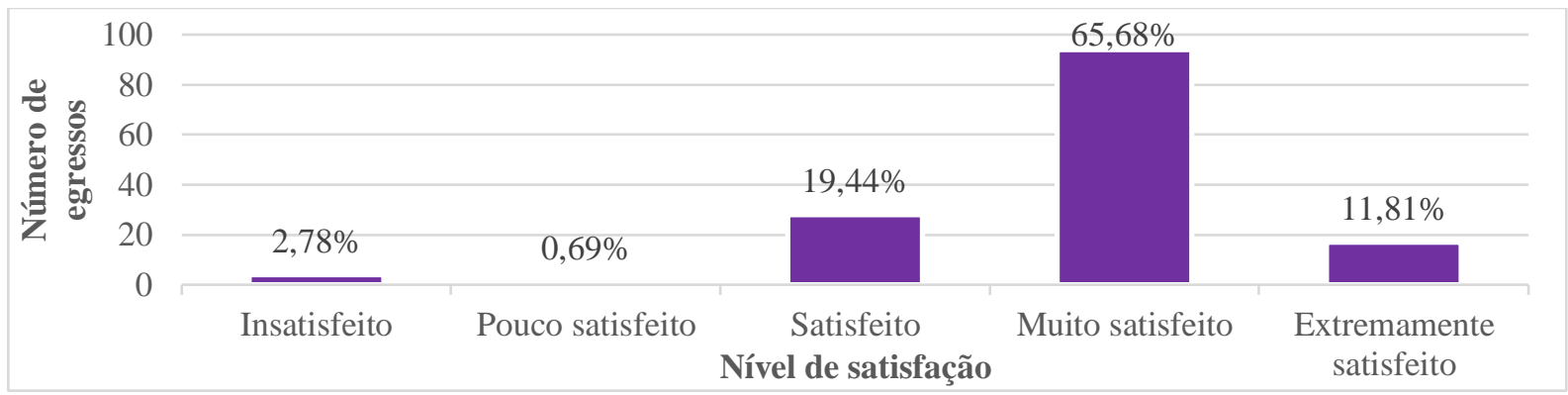

Fonte: Autoria própria

Na terceira seção do formulário foram coletados resultados referentes ao impacto do curso na renda e no desempenho profissional do egresso além da continuidade de sua formação.

Em relação à continuidade dos estudos, os resultados indicam que $67,3 \%$ dos participantes não possuem nem estão cursando uma especialização, sendo que $45,1 \%$ ainda têm interesse em fazê-lo. Dos demais, 14,6\% estão em curso e 18,1\% já tem uma ou mais especializações.

Em relação às pós-graduações stricto sensu, 27,8\% já concluíram o mestrado e 1,4\% o doutorado. Alguns egressos também estão com mestrado ou doutorado em curso: $13,2 \%$ e $13,9 \%$, respectivamente. Ainda, 34\% pensam em adquirir o título de mestre, o mesmo ocorre com $43,1 \%$ em relação ao título de doutor. O restante não tem interesse neste tipo de pósgraduação. Vale lembrar que dos $47,2 \%$ que optaram por uma pós-graduação stricto sensu, $27,8 \%$ o fizeram por vocação enquanto $19,4 \%$ em função da falta de emprego.

Com base nos resultados obtidos sobre a situação formal de trabalho (Figura 7), nota-se que a minoria dos egressos está desempregada (34,7\%). Mesmo com a ampla possibilidade de atuação uma quantidade relevante de egressos atua fora da área de formação $(31,9 \%)$ enquanto o restante está empregado na área $(33,3 \%)$. Isso reflete a necessidade de maior divulgação do curso para o meio empresarial e industrial. 
Figura 7 - Situação formal de trabalho dos egressos.

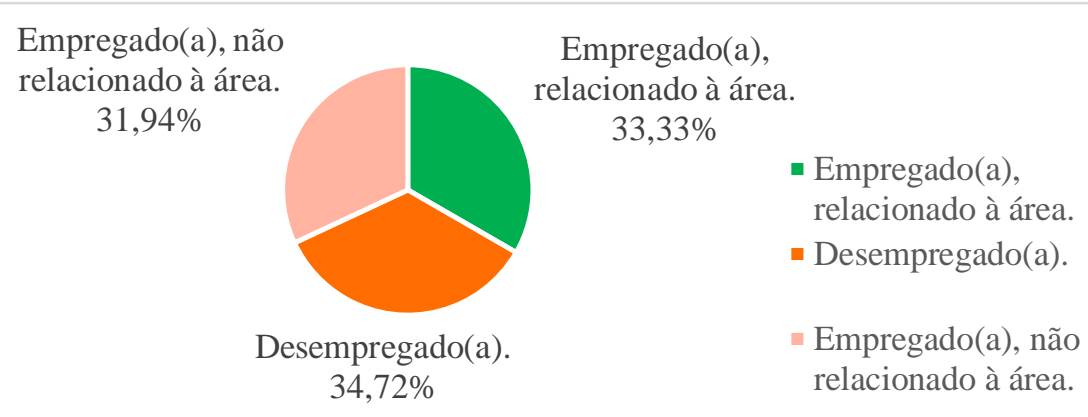

Fonte: Autoria própria

A atual situação do egresso foi analisada também em termos de níveis de dedicação: 28,5\% deles disseram ter que conciliar trabalho e estudo, 34,7\% possuem dedicação exclusiva aos estudos, $31,9 \%$ ao trabalho e o restante não trabalha nem estuda.

Sobre o tempo que os participantes levaram para conseguir o primeiro emprego, $30,6 \%$ disseram ainda não ter conseguido um. Apenas 18,8\% saíram da universidade empregados; os demais demoraram 6 meses ou mais para serem empregados. A busca pelo primeiro emprego ainda foi marcada por diversas dificuldades, tendo se destacado a exigência de experiência $(63,9 \%)$ e não ter encontrado emprego na área de formação $(51,4 \%)$.

Em relação ao porte da empresa e setor que os egressos trabalham, 26,4\% dos participantes estão empregados em empresas de grande porte e 47,2\% atuam no setor privado. Apenas 4,9\% dos egressos investiram em um empreendimento próprio, o que reflete a deficiência na formação empreendedora mostrada acima, e $16 \%$ atuam no setor público.

Somente $20,8 \%$ dos egressos realizaram intercâmbio internacional, dos quais 13,9\% acreditam que a experiência interferiu positivamente em sua trajetória profissional. É provável que a maior parte deles tenha tido acesso à esta experiência através do Ciência Sem Fronteiras, programa do Governo criado em 2011 para promover a expansão e internacionalização da ciência e da tecnologia através do intercâmbio internacional. Como os últimos bolsistas de graduação foram selecionados para o programa no ano de 2014, a oportunidade do intercâmbio tornou-se menos acessível novamente.

Em relação à renda mensal dos egressos, enquanto 43,1\% recebem de 1.500 a 3.000 reais, $6,3 \%$ ganham menos que isso. Outros $20,8 \%$ têm renda de 3.000 a 6.000 reais, enquanto somente $6,3 \%$ ganham mais que isso.

As atividades extracurriculares mais desenvolvidas foram iniciação científica $(49,3 \%)$, monitoria $(40,3 \%)$ e empresa júnior $(31,9 \%)$. Entretanto, $34 \%$ responderam que participar deste tipo de atividade não fez diferença ao conseguir um emprego em detrimento dos $31,9 \%$ que acreditam no contrário.

Quando questionados sobre como conseguiram seus empregos atuais, as formas mais comuns elencadas foram seleção de currículo $(22,2 \%)$ e indicação de pessoas influentes. Somente 6,3\% foram efetivados após o estágio.

Os resultados apontam que as funções que os egressos mais têm desempenhado são: laboratório (25\%), gestão $(14,6 \%)$ e escritório (9\%), mostrando que uma possível ênfase experimental no curso pode contribuir para melhores experiências no mercado.

Por fim, quanto ao nível de satisfação com sua situação profissional (Figura 8), variando de insatisfeito (1) a extremamente satisfeito (5), 38,2\% dos participantes atribuíram nota 4; 
$25,7 \%$ atribuíram nota 3 e 11,8\% nota 2 . Nos casos extremos $11,1 \%$ dos egressos se dizem insatisfeitos com sua situação profissional enquanto $13,2 \%$ estão extremamente satisfeitos.

Figura 8 - Nível de satisfação dos egressos com sua situação profissional.

\begin{tabular}{|c|c|c|c|c|c|c|}
\hline & 60 & & & & $19^{c}$ & \\
\hline$\stackrel{0}{\theta}$ & 40 & & & $25,69 \%$ & & \\
\hline อ & 20 & $11,11 \%$ & $11,81 \%$ & & & $13,19 \%$ \\
\hline & & 1 & 2 & Nível de satisfação & 4 & 5 \\
\hline
\end{tabular}

Fonte: Autoria própria

\section{CONSIDERAÇÕES FINAIS}

A metodologia utilizada neste trabalho se mostrou eficaz, sendo importante para o seu sucesso. Acredita-se que o simples envio do formulário não iria garantir a participação obtida, de forma que o contato direto com os ex-alunos por meio de ligações permitiu a retirada de dúvidas e um maior incentivo ao fornecimento de dados para a pesquisa.

A partir dos resultados obtidos, conclui-se que um dos maiores problemas enfrentados pelos egressos é de um mercado de trabalho que não conhece o Engenheiro de Bioprocessos, visto que apesar dos baixos salários, a maioria se encontra satisfeita com sua situação profissional e também com o curso.

O incentivo à participação de empresas que podem contratar este profissional em eventos do campus é uma possível solução para este problema, somado à uma campanha de divulgação sobre o curso.

\section{REFERÊNCIAS}

CBIOP. Sobre o curso. Universidade Federal de São João del-Rei. Ouro Branco, 2020. Disponível em: https://ufsj.edu.br/cbiop/sobre_o_curso.php. Acesso em: 14 mai. 2020. CUNHA, P. R.; BEUREN, I. M. Técnicas de amostragem utilizadas nas empresas de auditoria independente estabelecidas em Santa Catarina. Revista Contabilidade e Finanças., v. 17, n. 40, 2006. Disponível em:

http://www.revistas.usp.br/rcf/article/view/34178/36910. Acesso em: 27 mai. 2020. KIEHL, L. F. O tamanho da amostra na pesquisa de mercado. Revista de Administração de Empresas, v. 10, n. 4, 1970. Disponível em: https://www.scielo.br/pdf/rae/v10n4/v10n4a10.pdf. Acesso em: 27 mai. 2020. KRÜGER, J. RESOLUÇÃO no 1.108, de 29 DE NOVEMBRO DE 2018 - CONFEA. 2018. Disponível em: http://normativos.confea.org.br/ementas/visualiza.asp?idEmenta=67164 Acesso em: 22 jun. 2020. LOUSADA, A. C. Z.; MARTINS, G. A. Egressos como fonte de informação à gestão dos cursos de ciências contábeis. In: CONGRESSO USP DE CONTROLADORIA E CONTABILIDADE, 3, 2003, São Paulo. Anais. São Paulo: USP, 2003. Disponível em: http://www.revistas.usp.br/rcf/article/view/34151/36883. Acesso em: 25 mai. 2020. 
NUCCI, E et al. Projeto Pedagógico de Curso. Universidade Federal de São João del-Rei. Ouro Branco, 2017. Disponível em: https://ufsj.edu.br/portal2-

repositorio/File/cbiop/PPC\%20Engenharia\%20Bioprocessos\%202017\%20FINAL\%20CONE P\%20dez2.pdf. Acesso em: 14 mai. 2020.

PATINO, C. M.; FERREIRA, J. C. Intervalos de confiança: Uma ferramenta útil para estimar o tamanho do efeito no mundo real. Jornal Brasileiro de Pneumologia., v. 41, n. 6, 2015. Disponível em: https://www.jornaldepneumologia.com.br/detalhe_artigo.asp?id=2482. Acesso em: 27 mai. 2020.

SOLVIS. Cálculos de Amostragem: margem de erro. Disponível em: https://www.solvis.com.br/calculos-de-amostragem/ . Acesso em: 23 mai. 2020. UTFPR. Engenharia de Bioprocessos e Biotecnologia. 2018. Disponível em: http://www.utfpr.edu.br/cursos/coordenacoes/graduacao/toledo/td-engenharia-debioprocessos-e-biotecnologia/apresentacao Acesso em: 22 jun. 2020.

VIEIRA, M. A.; OHARA, C. V. S; DOMENICO, E. B. L. Construção e validação de instrumento para a avaliação de egressos da graduação em enfermagem. Revista LatinoAmericana de Enfermagem. São Paulo, 2016. Disponível em: https://www.scielo.br/pdf/rlae/v24/pt_0104-1169-rlae-24-02710.pdf. Acesso em: 25 mai. 2020.

\title{
ANALISIS OF THE BIOPROCESS ENGINEERING MAJOR AT THE SÃO JOÃO DEL-REI FEDERAL UNIVERSITY AS OF THE GRADUATES RESEARCH
}

\begin{abstract}
In the attempt to not only meet the work demands of Alto Paraopeba's zone but also diversify it, the São João del-Rei Federal University offers the Bioprocess Engineering major at Alto Paraopeba campus. The current article wants to perform a diagnosis of this course from a graduate research's view and justifies itself by the lack of the strategy management on graduates' portal of the university, due to the challenges of keeping a more effective communication tool between the graduates and the institution itself. Likewise the absence of an accurate former students' profile that bounds the Collegiate Body and the Structuring Teaching Core on improving and promoting the course throughout the society and the student body with these professionals' visions about the labour market. By way of a questionnaire, divided into three parts, parameters related to general aspects of the former students, the course itself, the campus and the labour market were quantified and qualified. The obtained results show, in general, that the leading problem faced by the graduates is the labour market that doesn't know the graduated Bioprocess engineer, for although the most part of them are satisfied with the course and their own professional situation, their remuneration is lower than the expected for their placements. More than a pointing research, the intention with this article is to inspire a new institucional way of keeping track of the graduates in a continued period of time to verify how they develop on the labour market and therefore measure the quality of education offered by the university.
\end{abstract}

Keywords: Graduates Research. Bioprocess Engineering. High Education. 